\section{Molecular biomarkers in studies on environmental cancer}

\section{K Husgafvel-Pursiainen}

\section{Molecular cancer epidemiology studies search for molecular effects associated with the aetiological factors involved in environmental cancer}

B iomarkers used for identification of risk factors of cancer in exposed populations have traditionally been classified into markers of exposure, effect, and susceptibility. ${ }^{12}$ Along with the advances in our knowledge about molecular biology, human genome, chemical carcinogenesis, and disease mechanisms, a variety of biomarkers of a more molecular nature have been launched and are currently being used widely in this field of research. ${ }^{3-5}$ This concept is often called, with some criticism, molecular epidemiology or molecular cancer epidemiology..$^{5-7}$ As illustrated by Porta and coauthors in their present paper, ${ }^{8}$ there has indeed been a dramatic increase in number of publications in this interdisciplinary field of research over the past decade or so.

In their article, Porta and his colleagues deal with certain aspects of molecular biomarker studies of cancer, in particular those relevant to studies investigating somatic mutations of genes controlling cell growth and differentiation such as DNA "fingerprints" - that is, indicators of the genotoxic nature of a chemical or exposure suspected of causal involvement. The authors themselves have performed several studies on $K$-ras mutations in pancreatic cancer, ${ }^{9-13}$ with outcomes suggesting associations between $K$-ras mutations and a number of environmental exposures or lifestyle factors. They have found that $K$-ras mutations in a series of exocrine pancreatic cancer cases show associations with tobacco and alcohol consumption, ${ }^{9}$ regular coffee drinking, ${ }^{10}{ }^{11}$ serum organochlorine concentrations, ${ }^{12}$ and occupational exposure to solvents. ${ }^{13}$ In their paper, ${ }^{8}$ Porta and colleagues discuss another recent study on pancreas cancer and $K$-ras mutations that failed to observe association with serum levels of organochlorines or PCBs. ${ }^{14}$ The authors refer to a number of points that they view as limitations in the US study. These points may, however, be of interest in more general terms, too.

The issues raised by Porta and coworkers need to be carefully taken into account when conducting studies examining the type and frequency of mutations as features related to tumours developed in the exposed. We have conducted a number of studies on lung cancer and some other types of occupational or environmental cancers using p53 and K-ras mutations as molecular biomarkers. ${ }^{15-20}$ This work has illustrated that matters related to the quality of the biomarker data, such as the quality of the tumour sample (fresh versus paraffin wax embedded tumour tissue)-and consequently that of the resulting DNA-, use of complementary techniques in mutation detection for increasing the sensitivity (for example, mutation screening combined with sequencing), strict criteria in sequence identification (for example, two independent PCR products), as well as issues of study design emerge all as crucial factors.

To highlight the value of molecular biomarker studies, another example, in addition to $K$-ras mutations in pancreatic cancer, can be discussed-that is, lung cancer, exposure to tobacco smoke, and p53 mutations. Extensive data on the biological effects of tobacco smoking, including its well documented genotoxicity, have strengthened the causal role of tobacco smoke exposure in lung cancer and largely justified use of biomarkers in studies on lung cancer and environmental tobacco smoke (ETS) also. ${ }^{21}$

It is well known that more than $50 \%$ of lung cancers carry a $p 53$ mutation. ${ }^{23}{ }^{24}$ We and others ${ }^{15} 20$ 25-27 have shown that smokers have significantly more $p 53$ mutations than non-smokers. The most common type of $p 53$ mutation is a guanine (G) to thymine ( $\mathrm{T}$ ) transversion, ${ }^{24}{ }^{26}$ and experimental evidence demonstrating the correspondence between mutational hotspots observed in lung tumours and formation of benzo(a)pyrene-and other polycyclic aromatic hydrocarbon (PAH) - DNA adducts exists. ${ }^{28}{ }^{29}$ Furthermore, $\mathrm{G}$ to $\mathrm{T}$ transversions, infrequent in human tumours other than $\mathrm{HCC}^{24}$ are currently believed to reflect the molecular signature of mutagenic constituents (especially that of benzo(a)pyrene and other $\mathrm{PAH}$ compounds) in tobacco smoke detectable in tumour DNA. ${ }^{30}$

In a European multicentre study on lung cancer among ETS exposed nonsmokers, we found that lifelong nonsmokers exposed to spousal ETS have an increased risk of $p 53$ mutations in comparison with non-exposed nonsmokers. ${ }^{20}$ This and other similar finding $\mathrm{s}^{27}$ provide support to other data suggesting that the development of lung cancer in ETS exposed non-smokers shares some key features, such as $p 53$ mutations, with that seen in smokers. Thus, molecular biomarkers found to be informative of biological alterations associated with high level exposure (smoking), may be used to give valuable information about low level exposure (ETS), often the most challenging environmental exposure situation to be investigated.

Recent work has determined that biological markers not only provide us information about exposure, effects, or susceptibility, but may serve as indicators of increased risk of cancer. ${ }^{31}$ A Nordic-Italian prospective cohort study observed that a high rate of chromosomal aberrations were significant predictors of cancer risk. ${ }^{32}$ More recently, a case-control study nested within the prospective Physicians' Health Study found that increased levels of PAH and other aromatic DNA adducts in white blood cells were able to predict the risk of lung cancer in current smokers. ${ }^{33}$

Molecular cancer epidemiology studies aim at elucidating the aetiology and molecular mechanisms of environmental cancers, with the ultimate goal for improved cancer prevention. Also, molecular markers may be of assistance in early detection and diagnosis, especially of diseases currently with long latency periods, late diagnosis, and poor prognosis such as lung cancer. ${ }^{34}$

In my view, despite the many weaknesses and methodological difficulties we still face today, as discussed here in depth by Porta and others, ${ }^{8}$ molecular biomarker studies are likely to provide us with tools valuable in risk assessment and in the prevention of environmental cancer, as we have already started to see. $^{35-37}$

$J$ Epidemiol Community Health 2002;56:730-731

\section{Author's affiliations}

K Husgafvel-Pursiainen, Finnish Institute of Occupational Health, Department of Industrial Hygiene and Toxicology, Topeliuksenkatu 41 aA, FIN-00250, Helsinki, Finland

Correspondence to:

Professor K Husgafvel-Pursiainen:

Kirsti.Husgafvel-Pursiainen@Htl.fi 


\section{REFERENCES}

1 Hulka B. Overview of biological markers. In: Hulka B, Wilcosky TC, Griffith JD, eds. Biological markers in epidemiology. New York: Oxford University Press, 1990.

2 Barrett JC, Vainio H, eds. Susceptibility to environmental hazards. Environ Health Perspect 1997;105 (suppl 4).

3 Harris CC. p53 tumor suppressor gene: at the crossroads of molecular carcinogenesis, molecular epidemiology, and cancer risk assessment. Environ Health Perspect 1996;104 (suppl 3):435-9.

4 Vainio $\mathrm{H}$, Husgafvel-Pursiainen $\mathrm{K}$. Mechanisms of carcinogenesis and molecular epidemiology. Br J Hosp Med

1996;56:162-70.

5 Perera FP. Environment and cancer: who are susceptible? Science 1997;278: 1068-73.

6 Hunter DJ. The future of molecular epidemiology. Int J Epidemiol 1999:28:S1012-14

7 Potter JD. At interfaces of epidemiology, genetics and genomics. Nat Rev Genet 2001;2: 142-7.

8 Porta M, Malats N, Vioque J, et al. Incomplete overlapping of biological, clinical and environmental information in molecular epidemiological studies: a variety of causes and a cascade of consequences. J Epidemiol Community Health 2002;56:XXX. [AQ:2]

9 Malats N Porta M, Corominas JM, et al. $\mathrm{Ki}$-ras mutations in exocrine pancreatic cancer: association with clinico-pathological chracteristics and with tobacco and alcohol consumption. Int J Cancer 1997;70:661-7.

10 Porta M, Malats N, Guarner L, et al. Association between coffee drinking and $\mathrm{K}$-ras mutation in exocrine pancreatic cancer. J Epidemiol Community Health 1999;53:702-9

11 Porta M, Malats N, Jariod M, et al. Serum concentrations of organochlorine compounds and K-ras mutations in exocrine pancreatic cancer. Lancet 1999;354:2125-9.

12 Porta M, Malats N, Alguacil J, et al., Coffee, pancreatic cancer, and K-ras mutations: updating the research agenda. J Epidemiol Community Health 2000;54:656-9.

13 Alguacil J, Porta M, Malats $\mathrm{N}$ et al. Occupational exposure to organic solvents and K-ras mutations in exocrine pancreatic cancer. Carcinogenesis 2002;23:101-6.
14 Slobos RJC, Hoppin JA, Tobert PE, et al. $\mathrm{K}$-ras and p53 in pancreatic cancer: association with medical history, histopathology and environmental exposures in a population-based study. Cancer Epidemiol Biomark Prev 2000;9: 1223-32.

15 Husgafvel-Pursiainen K, Kannio A. Cigarette smoking and p53 mutations in lung cancer and bladder cancer. Environ Health Perspect 1996;104 (suppl 3):553-6.

16 Kannio A, Ridanpää M, Koskinen H, et al. A molecular and epidemiological study on bladder cancer: p53 mutations, tobacco smoking and occupational exposure to asbestos. Cancer Epidemiol Biomarkers Prev 1996:5:33-9.

17 Husgafvel-Pursiainen K, Kannio A, Oksa P, et al. Molecular epidemiology of occupational cancer: mutations, tissue accumulation and serum levels of p53 in patients with asbestos and silica exposure. Environ Mol Mutagen 1997:30:224-30.

18 Roth S, Partanen T, Suitiala $T$, et al. Molecular analysis of occupational cancer: Infrequent p53 and ras mutations in renal cell cancer from gasoline-exposed workers. Int J Cancer 1997:73:492-6.

19 Husgafvel-Pursiainen K, Karjalainen A, Kannio $A$, et al. Lung cancer and past occupational exposure to asbestos: role of the p53 and K-ras mutations. Am J Respir Cell Mol Biol 1999:20:667-74.

20 Husgafvel-Pursiainen $K$, Boffetta $P$, Kannio $A$, et al. p53 Mutations and exposure to environmental tobacco smoke in a multicenter study on lung cancer. Cancer Res 2000;60:2906-11.

21 Law MR, Morris JK, Watt HC, et al. The dose-response relationship between cigarette consumption, biochemical markers and risk of lung cancer. Br J Cancer 1997;75: 1690-3.

22 Husgafvel-Pursiainen K. Biomarkers in assessment of exposure and biological effects of environmental tobacco smoke. Scand J Work Environ Health 200228 (suppl 2): 21-2.

23 Hollstein M, Sidransky D, Vogelstein B, et al. p53 mutations in human cancers. Science 1991;253:49-53.

24 Hussain SP, Harris CC. Molecular epidemiology of human cancer-contribution of mutation spectra studies of tumour suppressor genes. Cancer Res 1998;58:4023-7.
25 Suzuki H, Takahashi T, Kuroishi T, et al. p53 mutations in non-small cell lung cancer in Japan: association between mutations and smoking. Cancer Res 1992;52:734-6.

26 Hernandez-Boussard TM, Hainaut P. A specific spectrum of p53 mutations in lung cancer from smokers: review of mutations compiled in the IARC p53 database. Environ Health Perspect 1998;106:385-91.

27 Denissenko MF, Pao A, Tang M, et al. Preferential formation of benzo[a]pyrene adducts at lung cancer mutational hotspots in P53. Science 1996;274:430-2

28 Vähäkangas KH, Bennett WP, Castrén K, et al. p53 and K-ras mutations in lung cancers from former and never-smoking women. Cancer Res 2001;61:4350-6.

29 Smith LE, Denissenko MF, Bennett WP, et al. Targeting of lung cancer mutational hotspots by polycyclic aromatic hycrocarbons. I Natl Cancer Inst 2000;92:803-11.

30 Hainaut P, Pfeifer GP. Patterns of p53 G T transversions in lung cancers reflect the primary mutagenic signature of DNA-damage by tobacco smoke. Carcinogenesis 2001;22:367-74

31 Vineis $\mathbf{P}$, Perera F. DNA adducts as markers of exposure to carcinogens and risk of cancer. Int J Cancer 2000;88:325-8.

32 Hagmar L, Bonassi, S, Stromberg U, et al. Chromosomal aberrations in lymphocytes predict human cancer: a report from the European Study Group on Cytogenetic Biomarkers and Health (ESCH). Cancer Res 1998;58:4117-21

33 Tang D, Phillips DH, Stampfer $M$, et al. Association between carcinogen-DNA adducts in white blood cells and lung cancer risk in the Physician Health Study. Cancer Res 2001;61:6708-12

34 Perera F. Molecular epidemiology: on the path to prevention? J. Natl Cancer Inst 2000:92:602-12.

35 Blot WJ, McLaughlin JK. Passive smoking and lung cancer risk: what is the story now? [Editorial]. J. Natl. Cancer Inst 1998;90:1416-17

36 Potter JD. Colorectal cancer: molecules and populations. J Natl Cancer Inst 1999;91:916-32.

37 Brüning $\mathrm{T}$, Bolt $\mathrm{H}$. Renal toxicity and carcinogenicity of trichloroethylene: key results, mechanisms and controversies. Crit Rev Toxicol 2000;30:253-85. 